\title{
Iconicity and indexicality: The body in Chinese art
}

\author{
DAVID CLARKE
}

\section{Abstract}

This article examines the place of the body in Chinese art. It looks broadly at the case of literati painting and calligraphy and then offers a more historically focused examination of certain tendencies in modern Westerninfluenced Chinese painting, which was consciously antagonistic to literati values. Using Peirce's distinction between iconic and indexical modes of signification, it argues that while evocation of the body was important in literati visual culture, this was achieved primarily by indexical means, whereas in early twentieth century Chinese visual culture, iconic modes of representation were to become dominant. This modern contestation of the visual economy of literati painting is found particularly in paintings of the female nude.

\section{Indexicality and the sculpting of social space: Chinese literati painting and calligraphy}

Pre-modern European painting can be broadly characterized as privileging iconic signs because of its concern to make the represented space and its occupants as immediately present to the spectator as possible. European painting between the Renaissance and the appearance of modernism commonly attempted to dissolve the painted surface and open up an illusion of a three-dimensional world as if it existed before the viewing eye, abolishing spatial and temporal distance. It has achieved this denial of the gap between the moment of origin and the moment of reception by eliminating anything which draws attention to the body of the spectator, the space of viewing, and the time of viewing. The spectator must be constructed as a disembodied eye able to comprehend the whole image as if instantaneously. ${ }^{1}$ 
Awareness of the body of the artist, and the time and space of making, must also be inhibited for this mimetic art to succeed with its conjuring trick of presence. The artist, like the spectator, needs to be reduced to an eye, and the act of painting must be construed as if happening outside duration. At the level of actual painting practice, this goal requires an emphasis on what Norman Bryson (1983: 92) refers to as 'erasive' brushwork, that is, brushwork which does not draw attention to the painted surface or encourage the possibility of its being read as a trace of the artist's hand. ${ }^{2}$ We can characterize such brushwork as attempting to serve only an iconic function, and wishing to avoid being read indexically. Within mimetic painting indexical signs are disruptive of the illusion of presence: a trace of the movement of an artist's hand across the canvas is liable to bring awareness of the artist as an embodied being, of the process (the duration) of painting, and of the space of the work's making (that is, the space in front of the canvas as opposed to the space 'within' it).

Whereas indexical signs have to be suppressed or de-emphasized in European mimetic painting, Chinese literati painting and calligraphy, by contrast, foregrounds them. ${ }^{3}$ Brushstrokes are revealed as brushstrokes, as traces of the artist's hand, and in painting there has often been a preference for subjects, such as the bamboo, which permit the legibility of individual strokes. Furthermore, an elaborate aesthetic context exists in literati painting theory where these indexical marks are the subject of interpretation as marks.

In calligraphy, an art form central to literati values, the legibility of marks is at its highest level. Here we are able to read not just the individual strokes and the direction in which they were made, but also the sequence of their execution over time. This is possible not just because of the linear organization of writing, but also because of the conventional order in which the strokes of Chinese characters are written within any one script. This persistence at the level of forms is paralleled at the level of techniques and materials, making it possible for a member of the literati to empathize with a piece of calligraphy produced even many centuries earlier. According to Lothar Ledderose (1986) this is indeed a major social function of calligraphy, enabling a felt cohesion within the cultured elite (who were characteristically both viewers and makers of calligraphic art) over space and time - despite factional rivalries and actual historical discontinuities. Whereas in European mimetic painting the intrusion of indexical signs injures that art's ability to evoke the illusion of presence, in Chinese calligraphy it is the very existence of such signs which permits it. Only because Chinese literati brushwork allows its spectators empathy with the artist as an embodied being can they feel that the temporal and 
spatial barriers between viewer and maker are abolished. European mimetic painting seeks to hide the duration of making from awareness, but literati painting and calligraphy foregrounds the time of making, which the spectator, in the temporal process of viewing, as if retraces. A sense of immediacy is created: in the time of viewing, one is as if looking over the shoulder of the artist as the brushwork is produced, recapturing the artist's movements from the traces which they left. ${ }^{4}$

As well as emphasizing the time of making, literati painting and calligraphy also differs from European mimetic art in emphasizing the space of making. Even the paradigmatic space for viewing of literati painting is analogous to the space of making, further encouraging an empathic engagement during the viewing activity. While European art has for a long time characteristically encouraged a ritually separate space for art (and different separate spaces - the studio and the gallery - for making and for viewing) a Chinese literati handscroll being viewed in the (private) space of a scholar's study is not far from the kind of environment in which it was made. Not only is Western painting characteristically viewed in a ritually separate (and public) space but the etiquette requires that a ritual distance be observed from the image. At the preferred viewing distance the 'erasure' of brushwork is enhanced and the illusion of represented space made more convincing. A Chinese handscroll, by contrast, is - as the term suggests - to be handled: one can attain the bodily closeness to it enjoyed by its maker, unrolling it a part at a time to follow the artist's journey across the surface. The characteristic horizontal placement of the handscroll for viewing might also be taken as serving to undermine the illusion of represented space: for this particular genre of literati art at least, there is no analogy between paintings and windows at work as there so often is in the case of wall-hung Western paintings.

Although there is of course a represented space in a literati landscape scroll, for a variety of reasons it generally lacks the priority over the space of making enjoyed by the represented space of Western mimetic art. This is partly to do with our inability - reading the scroll portion by portion - to take in that space at one go, and partly to do with the absence of a unified perspectival viewpoint. In the case of a piece of Chinese calligraphy, as opposed to a painting, there is no represented three-dimensional space at all to offer a possible counterweight to the emphasis on the space of making. It is as absent as the space of making in Western mimetic art. Characters, like letters, have no volume, no 'body', and therefore they suggest no space around themselves. One can imagine no side views, no alternative aspects, on these abstract forms. 
Since calligraphy is often found on the surface of literati paintings, it provides another means by which whatever represented space those paintings do contain is devalued in importance. The brushstrokes from which the painted images are constructed become drawn, as it were, into the two-dimensional space of writing, to be considered in the same way as the calligraphic signs, as marks on a surface. That both written and painted marks are made in the same material (ink) with the same tool (the Chinese brush) of course helps the process of assimilating the one to the other. Chinese literati aesthetic theory has repeatedly affirmed the similarity of writing and painting, thereby serving to underline further what technique already seems to declare.

The calligraphy in literati painting tends to be put on an area of the surface not already occupied by the painting's own brushstrokes. This practice can be partly explained by the obvious desire to maximize the clarity of both writing and painting. However, since the emptier areas of a painting also often tend to be the ones furthest away in the image's representational space (usually the sky in the case of a landscape) calligraphy in those areas is particularly effective in canceling or inhibiting readings of deep space. This relationship between painted and written areas found its most fully developed form in the Qing dynasty, as Li Shan's Ink Bamboo hanging scroll (1749, collection Metropolitan Museum of Art, lent by John M. Crawford Jr.) demonstrates. ${ }^{5}$ A work by Zeng Yandong (Tseng Yen-Tung), reproduced as Plate 1 in Chiang (1938), has writing completely surrounding a human figure. This is something of an extreme case, but for that reason it offers a particularly striking example of the way calligraphy can condition our reading of space in a Chinese painting.

One should note that the calligraphy on literati paintings is not always by the artist or added at the time of the painting's making. I do not, however, consider this fact as undermining my argument since there are enough examples where the painter is the calligrapher to support it, and because cases where this is not so provide evidence concerning the reception of such art works that also helps my interpretation. They show how easy it was for the spectator to treat the surface of the painting as a surface. Those spectators who write on paintings or place their seals there go even further than empathically identifying with the space of making, they actually in a sense visit or inhabit it themselves. ${ }^{6}$

A particularly vivid example of seals and inscriptions being added to a pre-existing work is the Fengju Tie, a handscroll of three letters by Wang Xizhi in the collection of the National Palace Museum, Taipei although this is calligraphy rather than painting. Ledderose (1986) points out how the seals and inscriptions of various owners and other connois- 
seurs, including emperors of both the Song and Qing dynasties, have accumulated over time on this handscroll. Not only do such inscriptions attest to the ease with which their makers felt able to commune with the past, they also turn the work itself into a physical claim concerning cultural continuity for which it would be difficult to find parallels in European art.

For an example of inscription on painting we can also consider the seals placed on a Landscape (National Palace collection, Taipei) by Yuan dynasty painter Ni Zan. Some are seals placed by connoisseurs in appreciation, others are those of the various collectors to whom it had belonged during its history. Prominent among these is the oversize seal of the Qing dynasty emperor Qianlong, placed at the top centre. The relative crudity of this particular addition to the work perhaps betrays more clearly than is usually the case something of the power relations which are always involved in these communions with the past. From the point of view of the present such a piece may serve as a bearer of a myth of seamless cultural continuity, but from the point of the individual making the brush or seal mark on the painting's surface that act is an attempt to claim legitimacy, to produce (under the guise perhaps of homage) the sense of tradition as leading up to oneself. ${ }^{7}$ A similar process can also, of course, be at work in the painted images themselves. The painter one is communing with may himself be communing with, paying homage to, the style of an earlier artist. ${ }^{8}$ Like the consciously classical European artist, according to Norman Bryson's understanding (Bryson 1984), the literati artist must avoid being simply swamped by tradition, must contest it and appropriate its power for himself while appearing rather to respect it, or even to submit to it. Rupture must be presented as return, the move forward taken under the protective banner of (one's own chosen version of) the past. ${ }^{9}$

Although there are parallels, my understanding of literati brushwork differs from Bryson's understanding of European Neo-Classicism in that I do not see the issue involved as simply one of artistic power. That an emperor can also be a participant in the practice already makes that point clear, but it is not so much that collectors, and not only artists, are players in the game, as that in literati brushwork the positions of maker and viewer (or owner) are not anywhere near as distinct as they typically are with European art. A fluidity between these different positions (both actual and empathic) is a differentiating quality of the practice itself, allowing it to fulfill its role of helping to bind the social elite together, or (to put the point more strongly) helping to constitute that elite, to sculpt out a 'private' social space (both literally and metaphorically). ${ }^{10}$ 


\section{Iconicity and visual modernity: The nude in early twentieth century Chinese painting}

Given the particular differences of Chinese literati painting and calligraphy from European mimetic painting that I have attempted to clarify (albeit somewhat schematically) by means of a taxonomy of spaces, times, and bodies, and given (following Ledderose) the social function that its particular qualities help literati brushwork fulfill, one might surmise that there would be particular resistances to an incorporation of aspects of $\mathrm{Eu}-$ ropean mimetic painting within Chinese literati painting. Resistances at a systemic level, that is, which might inhibit the adoption of certain traits of European painting more than others. Significant features of European painting would have no place within literati visual culture, would find no point of purchase within it - but by the same token, if those features were adopted by a practice which wished to challenge literati cultural values, they would provide a resource which would oppose those values at almost every significant point.

To take one example, we might expect that a focus on the represented body (so common in European mimetic art) would be particularly difficult to assimilate within literati traditions since it would offer a counterweight to the focus on the body of the artist. From this perspective it is not so much that a Chinese painting practice influenced by European painting would be introducing a focus on the body absent in literati painting, but that it would be offering a challenge to literati painting by focusing on an alternative category of body from the one with which that practice was already deeply concerned. ${ }^{11}$

To narrow the focus down further we could consider the case of images of the female nude. Perhaps this type of represented body has been the most difficult to assimilate into Chinese ink painting, not just because the symbolic meanings it has in the European context are lacking (this would be true of other non-Western art contexts as well) but because of the particularly disruptive effects that would follow from an intrusion of a female image into the patriarchal process of communing with the traces of the masters' hands. The interest which so many Chinese painters of the early part of the twentieth century engaged in exploring the possibilities of European artistic media and styles displayed in the theme of the female nude must, I feel, come from their intuition that it is in some sense a 'radical' or 'modern' subject in the Chinese context, for reasons other than its mere intrinsic novelty. ${ }^{12}$ One would be underestimating the importance of what was taking place if one were to label these Chinese artists as 'backward' for only just having become interested in a theme which has been problematic in Western art at least since the time of Manet's Olympia. 
Such a manoeuvre would be a misconstrual of cultural differences as stages of development in an ethnocentrically conceived linear model. Of course, to say this is not to claim anything concerning the quality of the images involved (which varies immensely), nor is it exactly to present them as 'feminist' art, although there is perhaps something to be learned by Western feminism from the analysis of a visual culture which has sustained patriarchal structures without significant recourse to iconic representation of the female body.

A survey of periodicals and books published in China during the 1920s and 1930s demonstrates the popularity of the female nude as a subject during this time. ${ }^{13}$ Reproductions of images of the female nude by Chinese painters working in a style clearly influenced by European art are readily found. Female nudes by European painters, and (to a lesser extent) Japanese painters are also frequently reproduced. Taking the category of female nudes by Chinese artists for examination, we find a general tendency to represent the nude in a way which draws attention to the mass or the space-occupying volume of the figure. By this means, the emphasis on the represented body which the theme of the nude introduces is further accentuated. It is also underlined by the insistence of most images on the nude body as the subject in its own right, rather than as a carrier of complex mythological or allegorical schemes of meaning. As much as by the matter-of-fact treatment of the nude in the images themselves, this is conveyed by the choice of titles: we characteristically encounter not (say) The Birth of Venus but Human Body (Renti) ${ }^{14}$ - for example in works by $\mathrm{He}$ Tingyao and Zhu Shijie. ${ }^{15}$ A variety of static poses predominate, further helping to focus attention on the body itself. Movement would have the effect of drawing attention from the actor's body to the action, possibly introducing narrative interest and the opportunity for character to be displayed. Where an activity can be attributed to a static nude figure it tends to be either the activity of reverie, or the activity of posing. The former, seen for example in Figure 1 - Yang Jianhou's Daydreaming (Xia si) emphasizes the body since it presents the mind as somewhere else.

The number of works which depict figures posing (which make, that is to say, a conscious reference to the context in which these nude images were produced) is many. Paintings by Chen Shiwen, Lu Sibai, Gu Rucheng and Zhou Xijie (Figure 2) can stand as examples. To use a model (moter is the equivalent term in modern Chinese) to make an image of a model (as opposed to using a model to make an image of, for example, a bather, as appears to have been the case with Hu Yiwen's Woman by the Riverside [Figure 3]) is to introduce a reference to the space of making. But to refer to the space of making within the represented space is very different from the encouragement to empathically identify with the space 


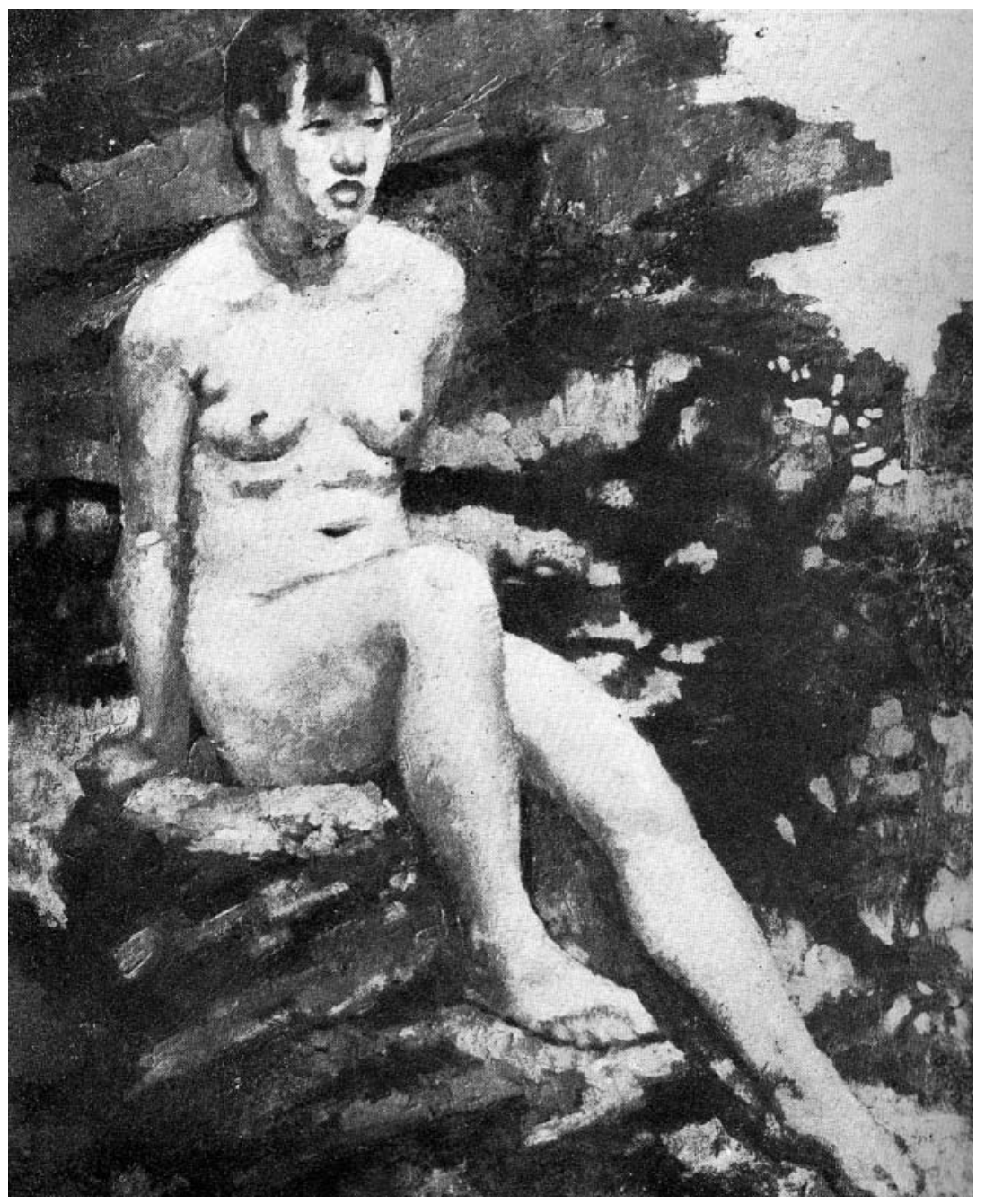

Figure 1. Yang Jianhou, Daydreaming (Xia si) (from Yi Feng, May 1935, 3 [5]: 134)

of making which I have argued literati painting offers. Indeed, the reference to a particular type of art production space that is distinctly different from that employed in literati practice explicitly lays bare for examination the departure from the literati paradigm.

The new type of art production place is the studio, and whether this is the private space of the professional artist's workroom or the more public space of the classroom, it differs from the literati scholar's study. It is a 


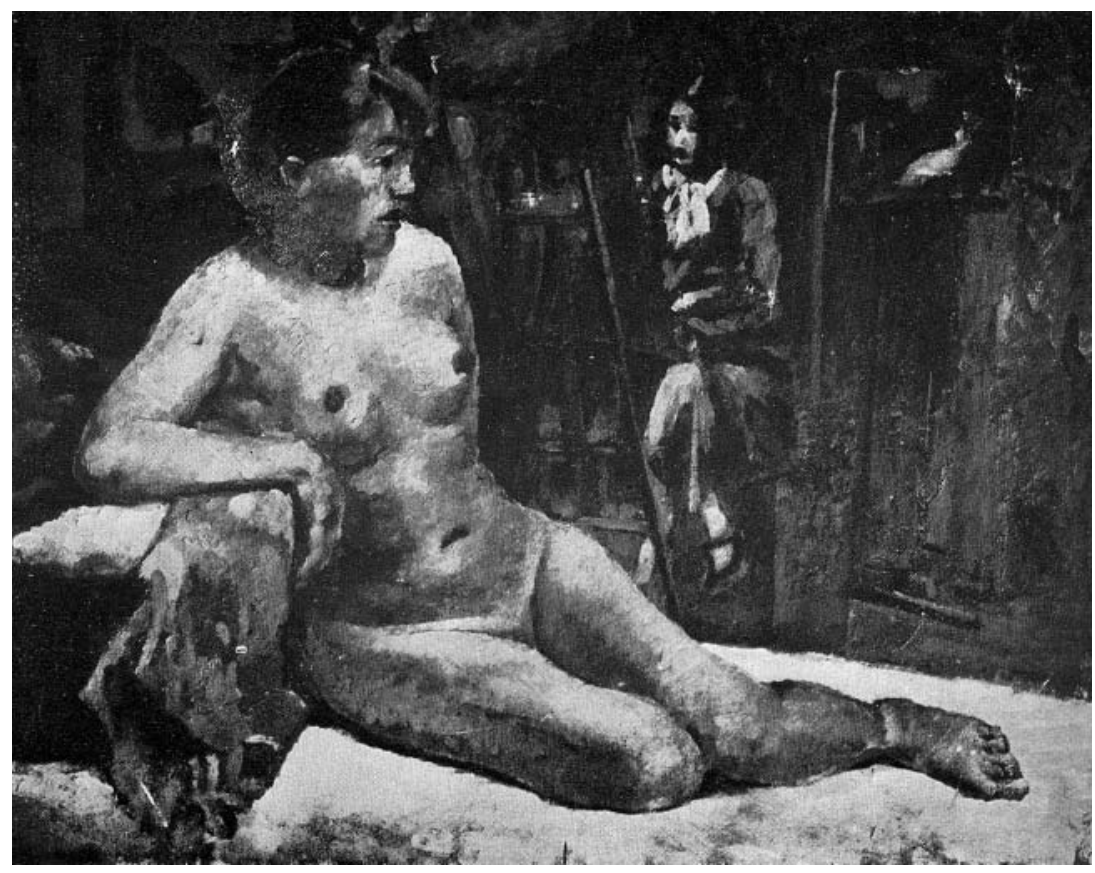

Figure 2. Zhou Xijie, Fanzuo (Study) (from Yi Feng, May 1935, 3 [5]: 138)

ritually separate space dedicated to the making of visual art, and not even to the viewing of it. Representing a nude model not only invokes this autonomous space for art production, it also alludes to a particular process of art making which takes place in such a space - namely, working from life - and to a particular (consciously innovative) method of art education which involves such a process. ${ }^{16}$

To point out the extent to which the genre of the nude is in opposition to all aspects of literati art practice, one could make a comparison with the case of calligraphy. If the nude is the genre which most requires working from life, this perhaps places it at the farthest remove from calligraphy, a genre where copying the masters is the only possible avenue for training. In respect of this genre it is not even possible to conceive of working from life rather than from tradition, of working from a female model instead of modeling yourself on a male precedent. The same orientation to the past is there whether one is working from a copybook (tie) containing reproductions of free-brushed works by great masters, or working from calligraphy carved on a ancient stele; whether one is 


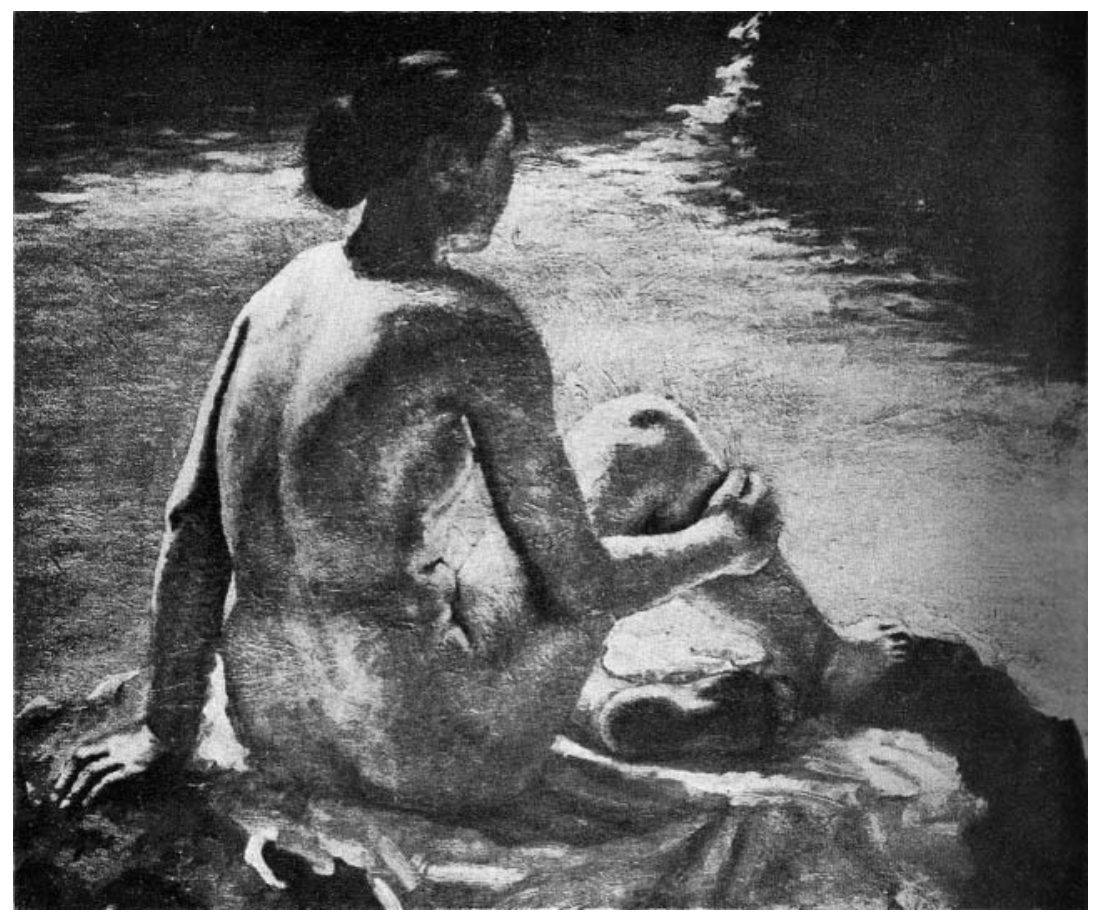

Figure 3. Hu Yiwen, Hepan nu (Woman by the Riverside) (from Yi Feng, May 1935, 3 [5]: 138)

making a freehand copy (lin) or self-consciously producing a work in a particular master's style ( fanggu) ${ }^{17}$

If we turn our attention to the historical evidence available concerning the reception of Western-influenced Chinese art we find that the nude was indeed a major focus of the debate and friction such consciously modernist art evoked. Attacks were made on paintings of the nude, on the use of nude models in the education process, and indeed on the models themselves. An exhibition held in 1915 by the Shanghai Art Academy, which included drawings of draped models, was denounced by a school principal (Kao 1972: 78). ${ }^{18}$ In 1926, the Academy's principal Liu Haisu was also at the centre of a row with the warlord Sun Chuanfang concerning nude models. Sun had banned their use, and Liu chose to debate the issue with him in the pages of the press. ${ }^{19}$ Lin Fengmian had a similar public row concerning the use of nude models with Liu Zhe, the Minister of Education (Kao 1992: 11).

Further evidence that the nude was particularly problematic in the Chinese context can be obtained from a variety of sources. A 1927 cartoon 
from Annals of Shanghai (Shanghai Chunqiu) comments on public incomprehension of the practice of using nude models by showing a crowd staring into an art studio where a naked female model is nonchalantly smoking a cigarette. A cartoon from 1935 (Figure 4) shows a crowd of people - some dressed Western-style, some more conservatively - in discussion before an exhibited female nude painting. ${ }^{20}$ A photo in another contemporary publication (Chou 1933) of a nude model in a studio at the Shanghai Art Academy bears the title 'Victims to Art'; while a film of the same year by the Great Wall Motion Picture Company, entitled Resurrection (Zaisheng), seems to have been about a painter of nudes. ${ }^{21}$ The concern of the authorities is displayed not only in their attempts to control the use of nude models in the Shanghai Art Academy, but also in a ban on the use of nude paintings as book cover illustrations. ${ }^{22}$

In Chinese periodicals of the 1920s and 1930s there was often discussion concerning the nude and the representation of the human body generally. The articles (by Ni Yide, Zhang Jingsheng, Yu Jifan, ${ }^{23}$ and others) in which it is to be found should be interpreted in relation to the broader debate over the value of study from life. Commonly, as in articles by Wang Yachen, Yu Jianhua, Jing Youlin and Lin Fengmian, ${ }^{24}$ study from nature and copying are presented as directly opposed methods. The latter is regarded as having become the norm in Chinese painting, and is seen as deadening in its effects on creativity. Jing Youlin makes this point most strongly, stating that even the work of someone who has mastered copying is comparable to the display of a corpse.

Whereas the practice of literati painting and calligraphy had taken place largely within the private social spaces of the pre-modern elite, the modernist art practice to which the paintings of the nude belong was occurring in a more public realm. Broader socioeconomic changes were, of course, helping to bring this wider public realm into being, but the modernist artists must be given credit for actively responding to the changing situation, and using available public space to contest inherited conceptions of aesthetic value. ${ }^{25}$ The debate took place, as the evidence introduced above demonstrates, not only within the narrower confines of specialist art magazines, but also in the broader social space of the public press. One reason, perhaps, why the nude became a key element in the debate was that it was an issue which could be a focus for discussion both in the more narrow attacks on literati artistic values, and in the more broadly framed (and largely preexisting) disputes concerning 'Western' or 'modern' values on the one hand, and 'Chinese' or 'Confucian' or 'traditional' values on the other.

It is clear that the nude was liable to become an emblem of broader controversies, although it was more often its opponents, rather than the 


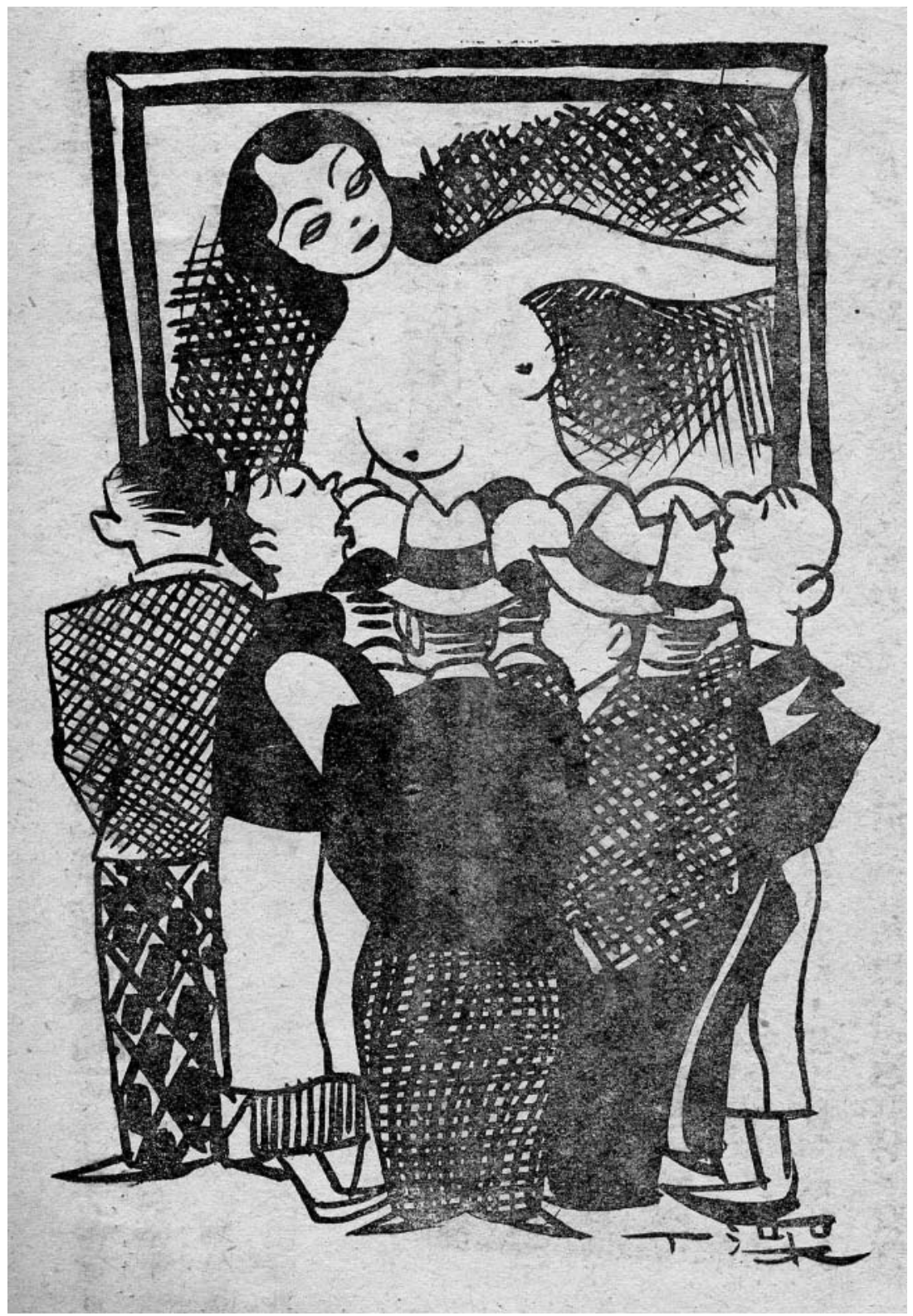

Figure 4. A cartoon concerning the audience for paintings of the nude (from Yi Feng, Shanghai, May 1, 1935, 3 [5]: 75) 
artists themselves, who were most explicit in linking it to larger social and political questions. Liu Haisu's use of nude models, for instance, is accused of being anti-Confucian, but (at least in the admittedly charged context of his newspaper debate with the authorities) he denies the accusation. In his published letters he is also careful to deny a link between artistic modernism and political activism (presumably because he thought it likely that such allegations might be made): he claims that his Academy's students have never been involved in student movement activities. The accusation Liu seems to fear was to be made in the case of Lin Fengmian, another pioneer in the use of the nude in art education, about a year later. Lin, some of whose students had been arrested, was to be accused of encouraging communist activities. (Chang 1992: 32)

Concerned more with establishing their own artistic autonomy and status (in contest with literati values), it would be a mistake to overemphasize the extent to which artists involved with the nude wished to place their art at the service of broader social and political goals, particularly leftist ones. In the case of Lin Fengmian, for instance, we do have evidence to document a relationship between artistic practice and a broader position, but it is to educational or cultural reform, rather than explicitly political positions as they are commonly understood, that we can link him. Lin played an important role in the reform of art education in China, being inspired by the philosophy of Cai Yuanpei, whom he knew personally. Like many intellectuals in China during the period following the May Fourth Movement, Lin placed great hope in educational and cultural means of revitalizing Chinese society, and looked to the West for resources. Art, taking over somewhat the former social role of religion, was to be a means of cultural revitalization itself, not a tool for other means of achieving this goal. ${ }^{26}$

Although its specific content remains somewhat difficult to decipher from the poor quality black and white reproductions which are all that remain of it, Lin's Suffering (Tongku) of 1929 deserves consideration as one of the most complex of the paintings produced in China during the 1920s and 1930s which make use of the female nude. In contrast to the other images of the female nude we have considered, Suffering does more than present the nude in a static, narrative-free context. This relatively large-scale work attempts to go one stage further and mobilize the nude female body as a bearer of elaborated meanings relevant to the Chinese context. A humanistic content that literati painting was not fitted to convey is addressed to an audience wider than that which literati painting had attempted to interpellate. The nude becomes a bearer of public meanings of a national nature, and (to state the case more strongly) becomes involved in an attempt to call a nationally conceived public into existence. 


\section{Notes}

1. Vermeer's View of Delft may be taken as a fully-developed work of the kind I am referring to here, but even when, as in Raphael's Marriage of the Virgin, a degree of bodily address to the spectator is present, it must be distinguished from that found in Chinese literati painting. The eye contact made with the spectator by one of the figures in the painting serves to strengthen the illusion of represented space, the effect of presence, not to undermine it. Unsurprisingly, when figures do appear in literati painting it is rather rare for them to display awareness of being looked at.

For Peirce's theory of the sign, see Buchler (1940). For Peirce on indexicality see Buchler (1940: 107-111); as well as Greenlee (1973). Sebeok (1990) provides a useful review of thinking about indexicality. The present essay extends my earlier studies of the relationship of iconic and indexical signs in art, which primarily consider European and North American examples: see Clarke (1992a, 1992b).

2. Bryson comments on Chinese art as well as Western art, and I have found his remarks about both artistic cultures suggestive. However, I feel he neglects to explore the social function of Chinese brushwork, and thus the indexical mode (this is my terminology not his) comes across in his discussion as superior to the iconic. Bryson's analysis of the way European mimetic painting fulfills extra-artistic functions (by embedding religious ideology in iconic detail, for instance), is, by contrast, particularly cogent. Freedberg (1989), drawing on a study of the reception of images, also offers a useful argument concerning the extent to which a relationship with the represented body is given a priority in much pre-modern European art. Again, the way an effect of bodily presence helps support a religious function is apparent.

3. Literati painting and calligraphy, the amateur art of China's scholar elite (often seen as having its beginnings in the eleventh century with the Song dynasty poet $\mathrm{Su} \mathrm{Shi}$ and his circle), has held a privileged status in China. Indeed literati brushwork has frequently been presented as standing for Chinese art as a whole, or as embodying the essence of Chinese culture. Recent scholarship, while still recognizing the hegemonic status of literati brushwork (or at least of literati aesthetic ideology), has tended to critique such monolithic or essentialist understandings of Chinese art, and has discovered amateur and professional practice to be less distinct than literati claims would lead one to think. Non-elite modes of art-making have been given greater attention, and the interaction between literati and professional practice has been analyzed. The present study is intended as a contribution to this new trend in the analysis of Chinese visual culture, and conceives of art as socially active within a dynamic, internally fragmented and contested cultural space.

4. On the body in Chinese art and culture see in particular Elvin 1989; Ames 1984; and Hay 1994.

5. Commenting on this work by Li Shan, Vito Giacalone claims that the character for bamboo, which appears several times in the poem, is 'written with the same brushstrokes as the image of the bamboo' (Giacalone 1986: 84). In Chinese and Japanese Calligraphy, Heinz Gotze also writes in more general terms about the similarity between Chinese depictions of bamboo and the character for it, arguing that 'the ink picture meets the script halfway, yet the script character has broken free from Nature and assumed a symbolic shape' (Komatsu and Wong 1989: 32). An early (Yuan dynasty) instance of a painter advising that the techniques of brushwork used in various calligraphic scripts can be adopted for the rendering of subjects favoured by literati painting is the inscription on a handscroll by Zhao Mengfu (see Cahill 1976: 162). The favoured subjects of literati painting tended to be those which did not require the higher 
level of painting skill found in works produced by professional artists: the relative absence of complicated effects of represented space in literati painting may in part be regarded as a consequence of the technical limitations of its more calligraphy-orientated amateur creators. In this text Chinese terms are generally given in pinyin romanization. Where a text is quoted in which other systems are used, the romanization given there is noted in brackets. Names in book or article references are left as romanized in the publication itself.

6. An extended discussion of inscription on painting is given in Sullivan 1980. The content of inscriptions (as opposed to the act of inscription itself) may also have a socially cohesive function. Either a reference to a friendship or to a painter of an earlier era would function in this way.

7. When an inscription by someone other than the artist was made soon after the painting's completion, as has frequently been the case, the sense of abolishing distance from the past would not be present. Nevertheless, one can still talk of the ease with which entry into the space of making occurred, of the role of empathy. Issues of power can still be present in such an instance, albeit differently balanced: a prestigious calligrapher could be invited to write on an image, thereby enhancing its artist's reputation. Yang Weizhen, for instance, supplied a colophon (dated 1361) to a handscroll by Zou Fulei. This inscription (which according to Yang's own words was made at the painter's invitation) consists mostly of a poem praising Zou and his late brother. An anecdote by Su Shi (see Fu 1977: 185) tells that his cousin, the painter Wen Tong, would deliberately leave space on his paintings for inscription, and not allow others to touch it until that prestigious writer had been given pride of place.

8. Li Shan, according to Vito Giacalone (1986: note 6), is using an album leaf by Dao Ji as his prototype. Cahill (1982: 116-126) discusses Ming dynasty painters' creative imitations of works by earlier artists such as Ni Zan.

9. One can see this process of struggle with the past taking place in the instance of the twentieth century Chinese ink painter, Zhang Daqian (Chang Dai-chien). The many ways he related his work to earlier Chinese art (including the production of forgeries) is discussed, albeit somewhat uncritically, in Fu 1991. Literati brushwork, despite its emphasis on precedent, can be said to allow rather more room for self-expression than European classicism, and this flexibility may have been a factor which helped preserve the practice. Even quite strongly individual expressions - of the kind only encountered in European art after the arrival of modernism - can occur without breaking the rules.

10. I take 'private' as referring not to a space outside of society, but to a particular type of social space, which may be constituted differently from one culture to another, and from one historical period to another. Similar points could be made concerning the term 'public', which is also employed in this text. My conception of subjecthood as constituted within particular cultural practices is indebted to the work of Foucault (especially Foucault 1977, 1990). The three part Fragments for a History of the Human Body (published in 1989 as Zone, vols. 3, 4, and 5) builds on Foucault's pioneering attempts to offer a historical account of the modes of social construction of the human body, and has also proved of use in the present study. In both of the texts by Foucault mentioned he tends to focus on regimes of control and the subjected body, and while I find his analysis of the micro-processes within which power is constituted suggestive, the practice of literati brushwork is one in which the agents are more active. Greenblatt (1980) offers theoretical resources for the study of a practice of that kind, although literati brushwork takes place in a less public domain than the activities he considers. To find a Western parallel to the socially-constitutive 'private' practice of literati 
brushwork one might look to the function of photography within the domain of the family, its role in the social reproduction of that institution. In the practice of family photography, image making and viewing can both (as with literati practice) take place in 'private' spaces of leisure, and there is a role for the amateur producer, a degree of fluidity between maker and viewer, in both cases.

11. The extent to which the spectator of Chinese brushwork can empathize with the artist as embodied is demonstrated by the comments of Chiang Yee (Chiang 1938). While somewhat idiosyncratic, Chiang's remarks are nevertheless revealing - particularly since they date from the same period as the modernist art discussed in this paper. They show that for him at least, calligraphy was felt to contain clues to somatic type, and not just to nobility of spirit conceived of in some abstract mental sense. Of a piece (his figure 47) by the Song emperor Huizong (Hui Tsung), he says 'his writing shows him to have been a tall, thin, handsome figure' (Chiang 1938: 83). Responding to an example (his figure 46) of calligraphy by Mi Fu (Mi Fei), on the other hand, Chiang writes: 'One thinks of a striking tubby figure walking along a road, unaware, apparently, of any one but himself' (Chiang 1938: 82). Of writing (his figure 36) by Ouyang Xun (Ou-Yang Hsun) he says: 'one imagines the artist to have been a well-built man with a fine, handsome appearance' (Chiang 1938: 71). Even Qing dynasty painter Dao $\mathrm{Ji}$, when wishing to assert the individuality of his style, must make somatic references, and point to the separateness of his body from those of the traditional masters:

I am always myself and must naturally be present (in my work). The beards and eyebrows of the old masters cannot grow on my face. The lungs and bowels (thoughts and feelings) of the old masters cannot be transferred into my stomach (mind). I express my own lungs and bowels and show my own beard and eyebrows. (Siren 1963: 188)

12. That the nude was absent from pre-modern Chinese art was noted by French missionaries of the eighteenth century. Conner (1986: 328) quotes one source of that date stating that 'Chinese painting was as careful to avoid the nude as European painting was anxious to expose it'. Even as late as 1934, in a letter written from Shanghai, American painter Mark Tobey was able to comment that 'the Chinese are not figure or nude conscious' (Mark Tobey, to Dorothy Elmhirst, 1934, Elmhirst Papers, Dartington Hall Archive, Devon, England).

13. Even at that time the ubiquity of the nude was commented upon. Lin Yutang (1936: 232) writes of a class of magazines which is 'constantly playing upon the nude motive', and refers to The Esthete ( $\mathrm{Wei} \mathrm{Mei}$ ) as a magazine "consisting of absolutely nothing besides nude pictures'. The presence of the nude in the popular press can be instanced by the case of the Pei-Yang Pictorial News (Beiyang Huabao) of Tianjin. Issues of this illustrated Chinese language publication from Volume 1 (1926) to Volume 21 (1933) frequently contained illustrations of paintings of the female nude by both contemporary Chinese artists (e.g., Lin Fengmian and Fang Junbi) and Western artists (e.g., Ingres and Rembrandt, as well as many lesser salon-style artists of more recent date, and occasional modernists such as Friesz), often juxtaposed with illustrations of earlier Chinese art. Cartoons concerning the nude are also to be found - e.g., in Beiyang Huabao (July 31, 1926, 1 [8]: 3) which comments on contemporary attitudes towards nude models - as can a large number of 'art photos' of the female nude, often of Western origin.

14. This term renti does not specifically connote nakedness in its most common usage, but would nowadays be understood as referring to the nude in an art context. 
15. Reference to the location of illustrations of images by Chinese artists mentioned in this section of the text are given here: He Tingyao, Human Body (Renti), in Yi Feng (February 1935: 89); Zhu Shijie, Human Body (Renti), in Yi Feng (May 1935: 135); Yang Jianhou, Daydreaming (Xia Si), in Yi Feng (May 1935: 134); Chen Shiwen, Oil paint study (Youhua fanzuo), in Yi Feng (April 1933: 93); Lu Sibai, title not known, in Yi Feng (September 1934: 12); Gu Rucheng, Human Body (Renti) in Yi Feng (October 1934: 48); Zhou Xijie, Study (Fanzuo), in Yi Feng (May 1935: 138); and Hu Yiwen, Women by the Riverside (Hepan nu), in Yi Feng (May 1935: 138). Much Westerninfluenced art of this period is knowable only from illustrations in contemporary periodicals, and all the aforementioned works must be presumed lost. I am grateful to Billy Kwan, Eve Tam, Chan Kuen-on, Silvia Fok and Feng Huanian for their help in assembling and translating certain materials used in this essay.

16. The earliest use of nude models in China may well have been in 1914, when Li Shutong (Hongyi Fashi), who had studied Western painting in Japan, introduced them to the Zhejiang First Normal School (Zhejiang Diyi Shifan Xuexiao). Worth consulting concerning early use of the nude in China are Li Shu (1962: 68-70); and Wu Mengfei (1959: 42-46). The latter has an illustration of a now lost nude painting by $\mathrm{Li}$, together with a photo of one of his life classes. Li became a Buddhist monk in 1918, giving up Western-style painting at that point. Draped models were also used in 1914 at the Shanghai Art Academy, and nude models soon after. A photo of a nude model in the life class at the Hangzhou West Lake National Art Academy (where French painter Andre Claudot was teaching) can be found in Wan and Clarke (1991: 1989). The earliest instances of Chinese artists displaying an interest in Western nude painting comes from Guangzhou. The artist known as Lamqua (who was active there till about 1860) made a copy of Ingres's Grande Odalisque, which he could only have known via engravings. Such a work, of course, was made for a Western market. Skillful though it may be, it remains purely a copy and would not have involved any encounter with a living model.

17. For a discussion of the various methods of copying calligraphy, see Fu (1977: 3-4). For a free imitation of a stele by Qing dynasty calligrapher He Shaoji, and a version of Wang Xizhi's Preface from the Orchid Pavilion (Lanting Xu) by Wen Zhengming of the Ming dynasty, see Fu et al. 1986. Female exclusion from calligraphy, like the exclusion of most males, was effected in pre-modern society by preventing their access to literacy. Even in more recent times, as Richard Curt Kraus notes (1991: 155), the vast majority of illiterates in China are female (nearly 70 percent of a 238 million total, according to the 1982 census).

18. Even at a later date, as photos show, models were not always completely nude. However, the Shanghai Pictorial Weekly (1933, 9 [36]: 35) ran an article claiming that female models were usually naked, whereas male models tended not to be.

19. The correspondence took place in the Shanghai newspaper Shen Bao (May 5, 13, 16, 17, and 18; June 10; July 1, 11, and 12, 1926). The letters have been collected in Zhuanji Wenxue (Biographical Literature), Taipei, 56 (3): 13-20 (number 334). See also Zhu Jinlou and Yuan Zhihuang 1987 for a further collection of primary texts concerning the issue of nude models; and Julia Andrews 2001 for an art historical analysis. I have benefited from discussions concerning the Shanghai Art Academy with Zheng Jie, whose own research on this institution has not been published at the time of writing.

20. The public discussion, and the space which enables it to occur, are of course as novel as the nude painting itself. The Sheying Huabao (1933, 9 [44]: 8) also has a cartoon of two men in front of a painting of a nude, and the Xianggang Gongshang Ribao (November 
$25,1934)$ has one of a man in 'traditional' dress who is represented as having been standing in front of a painting of a nude for a long time.

21. A photo relating to the film, and showing a nude model, an artist, and a nude painting appeared in the Shanghai periodical The Young Companion (Liangyou) (July 31, 1933, 78: 31). An advertisement concerning a public showing of a film about the aesthetics of the nude at the Beijing Art Academy (of which Lin Fengmian was the head) appeared in Chen Bao (Morning Post) (January 22, 1927).

22. Reported in Chen Bao (Morning Post, Beijing) (February 23, 1928: 7).

23. Ni Yide, 'Yishu shangde renti Biaoxian Kao' in Shenbao Yuekan (Shanghai) (September 1935, 4 [9]: 69-72); Zhang Jingsheng, 'Luoti Yanjiu - You Luohua Tandao Xuduo Shi', in Xinwenhua (Shanghai) (December 1926, 1 [1]: 52-68); Yu Jifan, 'Renti Zhi Xingshide Mei yu Biaoxiande Mei' in Shenbao Yuekan (June 15, 1933, 2 [6]: 105-110). Xiong Bingming, who had himself attended life classes in pre-communist China, recalls in 'Guanyu Luodan' ('About Rodin'), in Hsiung Shih Art Monthly (January 1983, 143: 120) that early Republican era artists influenced by Western thought criticized Chinese painting of women as being just clothes, as being 'bodiless' ( $w u t i)$.

24. Wang Yachen, 'Moxie Zirande Linghui' in Yifeng (Shanghai) (January 1, 1934, 2 [1]: 41-2); Yu Jianhua, 'Chuangzuo Yu Linmo' in Meizhan (Shanghai) (April 1929, 4: 7); Jing Youlin, 'You Mofang Dao Chuangzao, Yifengshe Meizhan Guangan' in Yifeng (July 1935, 3 [7]: 44); Lin Fengmian, 'Women Suo Xiwangde Guohua Qiantu' in Qiantu (January 1933, 1).

25. By the time the modernist art discussed here was coming into being, literati artistic culture in any real sense had already been undermined by the broader forces of socioeconomic change. 'Literati-style' art was still a contemporary target, however, as was the prestige of literati aesthetic values (which even merchants or Manchu emperors had found a place for).

26. The notion of art usurping the former role of religion is developed in Lin's 1927 essay 'Letter to the Entire Country's Art World' ('Zhi Quan Guo yishu jie shu'), in which he quotes Cai Yuanpei and follows closely the ideas that author had expressed in his essay 'Yi meiyu dai zongjiao shuo', first published in Xin Qingnian (August 1917, 3 [6]). On Lin's relationship with Cai, see Lin Wenzheng (1990: 1-3). I discuss Lin Fengmian's response to European art in Clarke (1993-1994: 22-29), and offer a broader discussion of twentieth century Chinese art in Clarke 2000.

\section{References}

Ames, Roger T. (1984). The meaning of body in classical Chinese thought. International Philosophical Quarterly 24 (1), 39-53.

Andrews, J. (2001). Luotihua lunzheng ji xiandai zhongguo meishude jiangou [The nude painting controversy and contemporary Chinese art history]. In Haipai huihua yanjiu wenji [Studies in Shanghai school painting], 117-150. Shanghai: Shanghai shuhua chubanshe.

Buchler, J. (ed.) (1940). The Philosophy of Peirce. London: Routledge and Kegan Paul. Bryson, N. (1983). Vision and Painting: The Logic of the Gaze. London: Macmillan. - (1984). Tradition and Desire. Cambridge: Cambridge University Press.

Cahill, J. (1976). Hills Beyond a River. New York: Weatherhill.

—(1982). Distant Mountains. New York: Weatherhill. 
Chang, A. (1992). Chronology. In The Art of Lin Fengmian, 31-37. Hong Kong: Hong Kong Arts Centre.

Chiang Yee (1938). Chinese Calligraphy. London: Methuen.

Chou, S. S. (1933). Shanghai Shi Daguan. Shanghai: Wen Hua Fine Arts Press.

Clarke, D. (1992a). The icon and the index: Modes of invoking the body's presence. American Journal of Semiotics 9 (1), 49-82.

- (1992b). The gaze and the glance: Competing understandings of visuality in the theory and practice of late Modernist art. Art History 15 (1), 80-98.

- (1993-1994). Exile from tradition: Chinese and Western traits in the art of Lin Fengmian. Oriental Art 39 (4), 22-29.

- (2000). Modern Chinese Art. Hong Kong: Oxford University Press.

Conner, P. (1986). For western eyes only: Chinese 'export' painting 1780-1850. Apollo 123, 328.

Elvin, Mark (1989). Tales of Shen and Xin: Body-Person and Heart-Mind in China during the last 150 years. In Fragments for a History of the Human Body (=Zone 4), M. Feher, R. Naddaff, and N. Tazi (eds.), 267-349. New York: Zone Books.

Foucault, M. (1977). Discipline and Punish. Middlesex: Penguin Books.

- (1990). The History of Sexuality, vol. 1. New York: Vintage Books.

Freedberg, D. (1989). The Power of Images. Chicago: University of Chicago Press.

Fu, Shen C. Y. (1977). Traces of the Brush: Studies in Chinese Calligraphy. New Haven: Yale University Art Gallery.

- (1991). Challenging the Past: The Paintings of Chang Dai-chien. Washington: Arthur M. Sackler Gallery.

Fu, Shen, Lowry, G. D., and Yonemura, A. (1986). From Concept to Context: Approaches to Asian and Islamic Calligraphy. Washington: Smithsonian Institution Press.

Giacalone, V. (1986). The John M. Crawford, Jr. collection of calligraphy and painting in the Metropolitan Museum of Art - II. Oriental Art 32 (1), 84.

Greenblatt, S. (1980). Renaissance Self-Fashioning. Chicago: Chicago University Press.

Greenlee, D. (1973). Peirce's Concept of the Sign. The Hague: Mouton.

Hay, John (1994). The body invisible in Chinese art? In Body, Subject, and Power in China, Angela Zito and Tani E. Barlow (eds.), 42-77. Chicago/London: The University of Chicago Press.

Kao, Mayching (1972). China's response to the West in art. PhD diss., Stanford University.

- (1992). Lin Fengmian: A butterfly broken free from its cocoon. In The Art of Lin Fengmian, 11-16. Hong Kong: Hong Kong Arts Centre.

Komatsu, S. and Wong, Kwan S. (eds.) (1989). Chinese and Japanese Calligraphy. Munich: Prestel.

Kraus, R. C. (1991). Brushes with Power. Berkeley: University of California Press.

Ledderose, L. (1986). Chinese calligraphy: Its aesthetic dimension and social function. Orientations 17 (10), 35-50.

Li Shu (1962). Woguo zuizaode jiwei youhuajia. Meishu (Beijing) 4, 68-70.

Lin Wenzheng (1990). Cai Yuanpei qizhong Lin Fengmian [Cai Yuanpei had a high regard for Lin Fengmian]. In Lin Fengmian Lun, Zheng Chao and Jin Shangyi (eds.), 1-3. Zhejiang: Zhejiang Meishu Xueyuan Chubanshe.

Lin Yutang (1936). Contemporary Chinese periodical literature. T'ien Hsia Monthly 2 (3), 232.

Sebeok, Thomas A. (1990). Indexicality. American Journal of Semiotics 7 (4), 7-28.

Siren, O. (1963). The Chinese on the Art of Painting. New York: Schocken Books.

Sullivan, M. (1980). The Three Perfections. New York: George Braziller. 


\section{D. Clarke}

Wan, Q. and Clarke, D. (1991). Faguo Huajia Anzhui Kelaoduo Ji Qi Zhongguo Zhi Xing. Hsiung Shih Art Monthly (Taipei) 242, 189.

Wu Mengfei (1959). Wusi yundong qianhoude Meishu Jiaoyi Huiyi Pianduan. Meishu Yanjiu 3, 42-46.

Zhu Jinlou and Yuan Zhihuang (eds.) (1987). Liu Haisu Yi Wenxuan. Shanghai: Shanghai Renmin Meishu Chubanshe.

David Clarke (b. 1954) is Associate Professor at the University of Hong Kong <dclarke@ hkucc.hku.hk >. His principal research interest is in modern and contemporary art (with a focus on Chinese art and on European and American art). Recent major publications include Modern Chinese Art (2000); Hong Kong Art: Culture and Decolonization (2001); and Reclaimed Land: Hong Kong in Transition (2002). 